\title{
The Relationship between Social Dominance Orientation and Dietary/Lifestyle Choices
}

\author{
Karin Braunsberger ${ }^{1, *}$, Richard O. Flamm ${ }^{2}$ and Brian Buckler ${ }^{3}$ \\ 1 Center for Entrepreneurship, University of South Florida, St. Petersburg, FL 33701, USA \\ 2 Florida Fish and Wildlife Conservation Commission, St. Petersburg, FL 33701, USA; \\ richard.flamm@myfwc.com \\ 3 School of Business, Avila University, Kansas City, MO 64145, USA; brian.buckler@avila.edu \\ * Correspondence: braunsbe@usf.edu
}

check for updates

Citation: Braunsberger, K.; Flamm, R.O.; Buckler, B. The Relationship between Social Dominance Orientation and Dietary/Lifestyle Choices. Sustainability 2021, 13, 8901. https://doi.org/10.3390/su13168901

Academic Editors: Miguel

Cuerdo Mir, Luis Miguel

Doncel Pedrera and

Jorge Sainz-González

Received: 3 June 2021

Accepted: 31 July 2021

Published: 9 August 2021

Publisher's Note: MDPI stays neutral with regard to jurisdictional claims in published maps and institutional affiliations.

Copyright: (c) 2021 by the authors. Licensee MDPI, Basel, Switzerland. This article is an open access article distributed under the terms and conditions of the Creative Commons Attribution (CC BY) license (https:// creativecommons.org/licenses/by/ $4.0 /)$.

\begin{abstract}
This research aims to: (1) examine the construct social dominance orientation (SDO) in a setting that expands group hierarchy to include prejudices and dominance toward animals; (2) compare predictive validity and internal consistency between the 16-item $\mathrm{SDO}_{6}$ and the 4-item $\mathrm{SSDO}_{\text {; }}$ and (3) test whether the $\mathrm{SDO}_{6}$ and the SSDO scales predict well in a consumer behavior oriented contextual setting. Predictive validity of the SSDO was almost as high as that of the $\mathrm{SSD}_{6}$; internal reliability, however, was considerably lower. Further, as hypothesized, individuals exhibiting lower levels of SDO, as assessed by both $\mathrm{SDO}_{6}$ and SSDO, exhibit lower levels of speciesism as well as higher levels of empathic concern. In addition, as hypothesized, ethical vegans, as compared to carnists, display lower levels of SDO and speciesism, and higher levels of empathic concern.
\end{abstract}

Keywords: social dominance orientation; $\mathrm{SDO}_{6}$; $\mathrm{SSDO}$; ethical vegan; omnivore; carnist; speciesism

\section{Introduction}

Social dominance theory [1] suggests that in addition to social group-based hierarchies that are grounded in age and gender and common in all social systems, societies that produce sustainable economic surplus also adopt structures of social hierarchies that are arbitrarily based on group traits such as ethnic group, race, species, and religion. Within these arbitrarily set structures, group conflict and repression are generally noted, and the existing prejudices and discrimination are not only reflections of the group-based social hierarchy but also help construct and sustain it. Individuals who uphold an established group hierarchy have been shown to exhibit high levels of social dominance orientation (SDO) - defined as an "individual difference orientation that expresses the value that people place on nonegalitarian and hierarchically structured relationships among social groups" [1], p. 61. For example, previous research has shown a strong correlation between SDO and discrimination, as well as prejudicial ideologies about numerous types of groups, including religious minorities, ethnic minorities, women, and the poor [2].

$\mathrm{SDO}$, as a measure of proclivity for prejudice, is usually assessed with the 16-item, 7-point, Likert-type $\mathrm{SDO}_{6}$ scale [3]. Even though $\mathrm{SDO}_{6}$ has been used extensively, it has been criticized for the relatively high number of scale items which is burdensome for both researcher and respondent. This common criticism targeted at longer scales has led to the trend of adopting shorter measures in personality research [4]. Another common criticism focuses on the widespread use of student samples, which has been blamed for inflating results in prejudice research [5]. Pratto et al.'s [2] research directly tackles these and other criticisms by testing the recently developed 4-item, 10-point, semantic differential Short Social Dominance Scale (SSDO) across 20 countries, using 15 languages, and show that the short scale is effective. In their research, Pratto et al. [2] focus on the relationship between SDO and attitudes toward aid to the poor, protecting minorities, and women in leadership 
positions. As anticipated, low scores on the SSDO scale indicate that an individual prefers group inclusion and favors equality over dominance.

The present research has several purposes. First, it compares predictive validity and internal consistency between the 16-item $\mathrm{SDO}_{6}$ and the 4-item SSDO in one set of studies, which to the best of our knowledge, has not been done. Second, it tests the construct social dominance orientation-a personality variable identified in psychology and used to predict social and political attitudes [6] - in a setting that expands group hierarchy to include prejudices and dominance toward animals; although this has been done previously, it has led to mixed results. That is, while Allen et al. [7] found a weak negative relationship between SDO and veganism, Dhont and Hodson's [8] results were more robust. It has been suggested that asking respondents to self-identify their dietary/lifestyle choices rather than using objective measures, in addition to not distinguishing among the different types of vegans, might be the reason for these mixed results [9]. Accordingly, the present study uses objective measures and distinguishes between types of vegans. The third purpose is to test whether the $\mathrm{SDO}_{6}$ and the SSDO scales predict equally well in a consumer-behavior oriented contextual setting as they have in traditional psychologically-based contexts. If this third purpose can be substantiated, then the final purpose is to introduce a construct that has been the focus of research in social, personality, and group psychology to consumer research and practice, where research on these types of constructs can provide ideas on how to develop successful messages designed to help battle environmental problems, such as pollution and climate change [10,11] and hyper-consumption [12].

\section{Social Dominance Orientation and Dietary/Lifestyle Choices}

The vegan market is rapidly gaining importance for marketing practitioners and researchers alike as the number of vegans has experienced a rapid growth rate [13-15], leading to a sharp increase in the sales of vegan products during the past several years $[16,17]$. Overall global vegan food sales are expected to grow at a compound annual growth rate of $9.1 \%$ to reach $\$ 24.3$ billion in 2026 [18]. For example, the global plant meat market is currently valued at $\$ 4.63$ billion and expected to reach $\$ 6.3$ billion by 2023 [19]. As a case in point, it took less than two years for Beyond Meat's bleeding vegan burger patty to expand its reach from Whole Foods to TGI Fridays, one of the largest casual dining chains in the US, as well as to Sysco, North America's largest food distributor. Furthermore, as of 2019, plant-based options have been available in fast-food chains, including Burger King, White Castle, and Hardee's [20]. Elmhurst Dairy in Queens, New York, one of the largest dairy manufacturers on the east coast of the US has completely replaced its dairy operations with plant-based milks [21].

It has been shown that individuals are driven by different motivations to take up a plant-based diet, such as animal-related motives, self-related motives, and environmentrelated motives, and that these motives help predict individuals' attitudes toward animal agriculture as well as how long they remain vegan, with those driven by animal-related motives reporting to having followed a vegan diet for significantly longer than other types of vegans [22]. Accordingly, it has been suggested that marketers differentiate among the motives and then tailor their messages to specific segments in order to increase sales [22]. Hence, when comparing the 16-item $\mathrm{SDO}_{6}$ to the 4-item SSDO, we focus on contrasting omnivores who, in the Western world, generally adhere to "the belief system in which eating certain animals [e.g., cows, pigs, etc., but not dogs, cats, etc.] is considered ethical and appropriate" and have been named carnists [23] to those individuals who embrace ethical veganism, which has been defined as the "personal rejection of the commodity status of nonhuman animals, of the notion that animals have only external value, and of the notion that animals have less moral value than do humans" [24]. In other words, ethical vegans are "vegan for the animals," embrace animal rights, and therefore can be expected to be against the currently dominant hierarchy that considers animals to be lesser beings and accordingly display a lower level of SDO than carnists. Thus, the first hypothesis states: 
Hypothesis 1 (H1). Carnists display significantly higher levels of SDO, as measured by both $\mathrm{SDO}_{6}$ and SSDO scales, than ethical vegans.

For that reason, both $\mathrm{SDO}_{6}$ and SSDO scales should be correlated to speciesism, which has been defined as "a prejudice or attitude of bias in favor of the interests of members of one's own species and against those of members of other species" [25]. Speciesism has been ingrained into the dominant Western food culture, namely carnism, and it is of interest to this group to maintain a status quo that promotes the belief that it is ethical and appropriate to consume the meat of certain animals [23]. Thus, it is expected that carnists will display a higher level of speciesism than ethical vegans. Therefore, the second hypothesis posits:

Hypothesis 2 (H2). Carnists display significantly higher levels of speciesism than ethical vegans.

Further, $\mathrm{SDO}_{6}$ and SSDO scales will be correlated with empathic concern, with the added expectation that carnists will display a lower level of empathic concern-defined as "the degree to which the respondent experiences feelings of warmth, compassion and concern for the observed individual" [26] - than ethical vegans. This expectation is based on prior findings that show that vegans who anthropomorphize animals display higher levels of empathic concern toward animals [27] and that lacto-ovo vegetarians (i.e., individuals who consume eggs and dairy but no meats) display lower levels of empathy than vegans [28]. Accordingly, the third hypothesis states:

Hypothesis 3 (H3). Carnists display significantly lower levels of empathic concern than ethical vegans.

\section{Methods}

All data were collected in two steps. First, participants were obtained through the Harris Panel, including members of its third-party panel providers. Although quota sampling (vegan versus nonvegan) was employed, ethical vegans were under-represented in the sample. Thus, during the second step of data collection, the assistance of animal rights and vegan organizations in the US (e.g., Vegetarian Resource Group, Mercy for Animals) was employed to help recruit ethical vegan respondents. We used a betweensubjects design employing two online surveys. These surveys were identical to each other, except for the measure of SDO; that is, one of the surveys included the $\mathrm{SDO}_{6}$ and the other survey featured the SSDO.

\subsection{Study 1: Data Analyses-SDO 6}

Dietary choice was assessed by asking respondents to specify which of the provided five food choice categories most closely resembled their eating habits. Given that the current research centers on investigating differences between carnists and vegans, just two of the food choice categories were pertinent, namely I eat red meats and other foods and I do not eat any type of meat or any animal byproducts [adapted from 13]. Further, as not all vegans are ethical vegans, all vegan respondents were subsequently asked to indicate their main motivation for going vegan and were given choices that included my health, animal rights, weight loss, the environment, my religion, my spiritual beliefs, world hunger, and saving money.

Of the 295 subjects completing the survey featuring $\mathrm{SDO}_{6}, 140(47.5 \%)$ stated that they consume red meat and are thus deemed to be carnists. A total of $79(26.8 \%)$ of respondents reported that they do not eat any type of meat or any animal byproducts and are ethical (i.e., animal rights) vegans. The remaining $76(25.8 \%)$ of respondents were either pescopollo vegetarians (i.e., avoid red meat but eat fish and/or poultry), lacto-ovo vegetarian (i.e., do not eat any type of meat, but consume eggs and/or dairy), or went vegan for non-animal rights reasons and were therefore excluded from the analysis (see Table 1 for the demographic profile of the reduced sample). 
Table 1. Demographic characteristics of study 1 sample $(\mathrm{N}=219)$.

\begin{tabular}{llcc}
\hline & & Frequency & Percent \\
\hline Gender & Male & 91 & 41.6 \\
Age & Female & 128 & 58.4 \\
& $18-20$ & 13 & 5.9 \\
& $21-29$ & 49 & 22.4 \\
& $30-39$ & 43 & 19.6 \\
& $40-49$ & 35 & 16.0 \\
& $50-59$ & 36 & 16.4 \\
Current Relationship Status & 23 & 10.5 \\
& $60-69$ & 20 & 9.1 \\
& 70 or older & 106 & 48.4 \\
& Married & 5 & 2.3 \\
& Widowed & 18 & 8.3 \\
& Divorced & 1 & 0.5 \\
& Separated & 9 & 4.1 \\
& In domestic partnership or civil union & 21 & 9.6 \\
& Single, but cohabiting with a significant other & 59 & 26.9 \\
& Single, never married & 3 & 1.4 \\
& Less than high school degree & 26 & 11.9 \\
& High school degree or equivalent (e.g., GED) & 48 & 21.9
\end{tabular}

\subsection{1. $\mathrm{SDO}_{6}$}

The reliability of the scale was very high $(\alpha=0.91)$, and all 16 items did well on the Cronbach's Alpha measure. We first ran an unrotated principal axis factor analysis on the data, which revealed two factors. The first factor had an eigenvalue of 7.04 and explained $44.01 \%$ of the variance; the second factor had an eigenvalue of 3.44 and explained $21.52 \%$ of the variance. Both factors together featured explanatory power of $65.53 \%$. The rotated factor analysis, using Varimax, showed that the first factor summarized the eight items that have been shown to measure SDO-Dominance and the second factor the eight items that measure SDO-Egalitarianism [29] (see Table 2 for items means, standard deviations, and factor loadings).

Table 2. $\mathrm{SDO}_{6}$, scale items, item means and standard deviations, and factor loadings.

\begin{tabular}{|c|c|c|c|}
\hline \multicolumn{4}{|c|}{ SDO-Dominance: Preference for Some Groups to Dominate Others/Support for Group-Based Dominance Hierarchies } \\
\hline & Item Means & SD & Factor 1 Loadings \\
\hline Some groups of people are just more worthy than others. & 2.55 & 1.85 & 0.728 \\
\hline In getting what your group wants, it is sometimes necessary to use force against other groups. & 2.89 & 1.81 & 0.720 \\
\hline Superior groups should dominate inferior groups. & 2.49 & 1.73 & 0.821 \\
\hline To get ahead in life, it is sometimes necessary to step on other groups. & 2.90 & 1.84 & 0.804 \\
\hline If certain groups of people staved in their place, we would have fewer problems. & 2.85 & 1.93 & 0.827 \\
\hline It's probably a good thing that certain groups are at the top and other groups are at the bottom. & 2.88 & 1.90 & 0.764 \\
\hline Inferior groups should stay in their place. & 2.38 & 1.68 & 0.836 \\
\hline Sometimes other groups must be kept in their place. & 2.84 & 1.84 & 0.849 \\
\hline \multicolumn{4}{|c|}{ SDO-Egalitarianism: Preference for Nonegalitarian Intergroup Relations/Opposition to Group-Based Equality } \\
\hline & Item Means & SD & Factor 2 Loadings \\
\hline It would be good if all groups could be equal. * & 2.33 & 1.56 & 0.845 \\
\hline Group equality should be our ideal. * & 2.45 & 1.64 & 0.856 \\
\hline All groups should be given an equal chance in life. * & 1.73 & 1.18 & 0.608 \\
\hline We should do what we can do to equalize conditions for different groups. * & 2.44 & 1.61 & 0.822 \\
\hline Increased social equality would be a good thing. ${ }^{*}$ & 2.09 & 1.49 & 0.818 \\
\hline We would have fewer problems if we treated different groups more equally. * & 2.31 & 1.56 & 0.839 \\
\hline We should strive to make incomes more equal. * & 2.53 & 1.78 & 0.777 \\
\hline No one group should dominate in society. ${ }^{*}$ & 2.18 & 1.51 & 0.658 \\
\hline
\end{tabular}

Note: Jost and Thompson [3], 1 = strongly disagree/disapprove; 2 = disagree; 3 = somewhat disagree; 4 = neither disagree nor agree; $5=$ somewhat agree; $6=$ agree; $7=$ strongly agree $/$ approve; ${ }^{*}$ reverse coded.

One aim of the present research is to compare $\mathrm{SDO}_{6}$ and SSDO. Since Pratto et al. [2] found that the SSDO scale only had one dimension, and our hypotheses do not advance differential outcomes depending on teasing apart SDO-Dominance and SDO-Egalitarianism, the 16-item scale was collapsed into a summary variable $(\mathrm{m}=2.49$; $\mathrm{SD}=1.11$; range $=6.0)$, where higher scores denote a higher level of SDO. 


\subsubsection{Speciesism}

The speciesism scale consists of eight 7-point Likert items [30] (see Table 3 for item means, standard deviations, and Cronbach's Alpha). Higher scores on the summary measure $(\mathrm{m}=3.22 ; \mathrm{SD}=1.56$; range $=5.38)$ signify a higher level of speciesism.

Table 3. Speciesism scale items, item means, and standard deviations.

\begin{tabular}{|c|c|c|c|c|}
\hline & \multicolumn{2}{|c|}{ Study $1 ; N=219 ; \alpha=0.88$} & \multicolumn{2}{|c|}{ Study $2 ; N=290 ; \alpha=0.90$} \\
\hline & Item Means & SD & Item Means & SD \\
\hline Animal research cannot be justified and should be stopped. * & 3.30 & 2.08 & 2.82 & 2.08 \\
\hline $\begin{array}{l}\text { The production of inexpensive meat, egg, and dairy products justifies maintaining } \\
\text { animals under crowded conditions. }\end{array}$ & 2.72 & 1.94 & 2.19 & 1.80 \\
\hline The use of animals in rodeos and circuses is cruel.* & 2.94 & 1.91 & 2.34 & 1.88 \\
\hline I get upset when I see wild animals in cages at zoos. * & 3.33 & 2.08 & 2.62 & 1.94 \\
\hline $\begin{array}{l}\text { I think it is perfectly acceptable for cattle, chickens, and pigs to be raised for human } \\
\text { consumption. }\end{array}$ & 4.32 & 2.53 & 3.30 & 2.51 \\
\hline I have seriously considered becoming a vegetarian in an effort to save animal lives. ${ }^{*}$ & 4.10 & 2.57 & 3.04 & 2.49 \\
\hline I think human economic gain is more important than setting aside land for wildlife. & 2.48 & 1.69 & 2.05 & 1.56 \\
\hline There is nothing wrong with killing animals for their fur to make clothes (fur coats). & 2.58 & 1.99 & 2.19 & 1.78 \\
\hline
\end{tabular}

Note: Dhont et al. [30]; 1 = strongly disagree to $7=$ strongly agree; ${ }^{*}$ reverse coded.

\subsubsection{Empathic Concern}

The empathic concern scale was adapted from Davis [26] to be comprised of seven 7-point items (assessed from $1=$ does not describe me well to $7=$ describes me very well). Higher scores on the summary measure $(\mathrm{m}=5.40 ; \mathrm{SD}=1.17$; range $=5.29)$ show a higher level of empathic concern (see Table 4 for item means, standard deviations, and Cronbach's Alpha).

Table 4. Empathic concern scale items, item means, and standard deviations.

\begin{tabular}{|c|c|c|c|c|}
\hline & \multicolumn{2}{|c|}{ Study $1 ; N=219 ; \alpha=0.84$} & \multicolumn{2}{|c|}{ Study $2 ; N=290 ; \alpha=0.83$} \\
\hline & Item Means & SD & Item Means & SD \\
\hline \multirow{7}{*}{$\begin{array}{l}\text { When I see someone being taken advantage of, I feel kind of protective toward them. } \\
\text { When I see someone being treated unfairly, I sometimes don't feel very much pity for } \\
\text { them. * } \\
\text { I often have tender, concerned feelings for people less fortunate than me. } \\
\text { I would describe myself as a pretty soft-hearted person. } \\
\text { Sometimes I don't feel sorry for other people when they are having problems. * } \\
\text { Other people's misfortunes do not usually disturb me a great deal. * } \\
\text { I am often quite touched by things that I can see happen. }\end{array}$} & 5.61 & 1.53 & 5.96 & 1.42 \\
\hline & 5.74 & 1.65 & 6.03 & 1.55 \\
\hline & 5.34 & 1.61 & 5.89 & 1.45 \\
\hline & 5.28 & 1.65 & 5.59 & 1.55 \\
\hline & 5.01 & 1.81 & 5.07 & 1.97 \\
\hline & 5.40 & 1.71 & 5.60 & 1.70 \\
\hline & 5.42 & 1.61 & 5.81 & 1.41 \\
\hline
\end{tabular}

Note: adjusted from Davis [26]; measured from 1 = does not describe me well to 7 = describes me very well; * reverse coded.

\subsubsection{Correlations}

Pearson correlations show a strong, highly significant, positive relationship between speciesism and $\mathrm{SDO}_{6}(\mathrm{r}=0.514 ; p=0.000)$ as well as a moderate, highly significant, negative relationship between empathic concern and $\mathrm{SDO}_{6}(\mathrm{r}=-0.456 ; p=0.000)$ (see Table 5 for more detail on the statistical analyses). 
Table 5. Statistical details for $\mathrm{SDO}_{6}$ and SSDO scales.

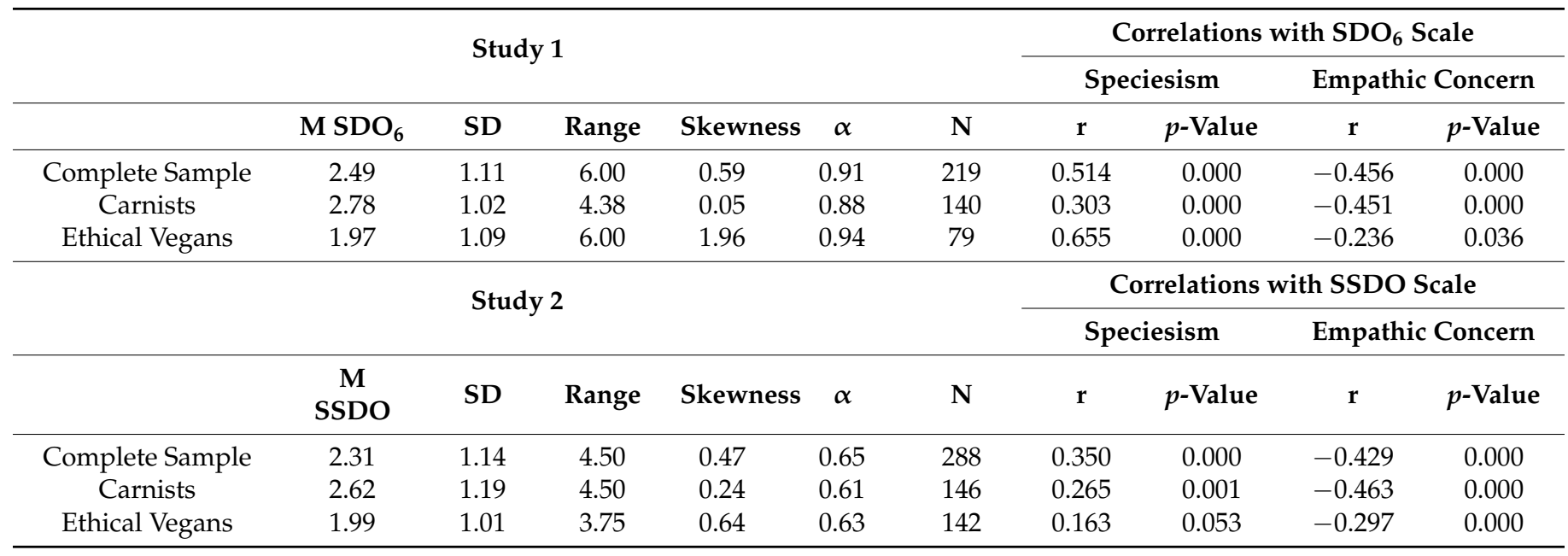

\subsubsection{One-Way ANOVA}

One-way ANOVA was used to test the hypotheses. The analyses show, as theorized, that ethical vegans exhibit a statistically significant (1) lower level of SDO $(\mathrm{m}=1.97$; $\left.\mathrm{F}=30.169 ; p=0.000 ; \eta^{2}=0.122\right)$ than carnists $(\mathrm{m}=2.78) ;(2)$ lower level of speciesism $\left(\mathrm{m}=1.52 ; \mathrm{F}=449.996 ; p=0.000 ; \eta^{2}=0.675\right)$ than carnists $(\mathrm{m}=4.18)$; and $(3)$ higher level of empathic concern $\left(\mathrm{m}=5.98 ; \mathrm{F}=35.188 ; p=0.000 ; \eta^{2}=0.140\right)$ than carnists $(\mathrm{m}=5.07)$. The three partial eta square values $\left(\eta^{2}\right)$ show effect sizes that are medium to large. (See Tables 6 and 7 for more detail on the statistical analyses). Therefore, $\mathrm{H}_{1}, \mathrm{H}_{2}$, and $\mathrm{H}_{3}$ can be supported.

Table 6. Study 1 descriptive statistics.

\begin{tabular}{|c|c|c|c|c|c|c|c|}
\hline & & \multirow[b]{2}{*}{$\mathbf{N}$} & \multirow[b]{2}{*}{ Mean } & \multirow[b]{2}{*}{ SD } & \multirow[b]{2}{*}{ Std. Error } & \multicolumn{2}{|c|}{$95 \%$ Confidence Interval for Mean } \\
\hline & & & & & & Lower Bound & Upper Bound \\
\hline \multirow[t]{3}{*}{$\mathrm{SDO}_{6}$} & Carnists & 140 & 2.78 & 1.02 & 0.086 & 2.6099 & 2.9500 \\
\hline & Ethical Vegans & 79 & 1.97 & 1.09 & 0.122 & 1.7306 & 2.2172 \\
\hline & Total & 219 & 2.49 & 1.11 & 0.075 & 2.3413 & 2.6370 \\
\hline \multirow[t]{3}{*}{ Speciesism } & Carnists & 140 & 4.18 & 0.92 & 0.078 & 4.0270 & 4.3355 \\
\hline & Ethical Vegans & 79 & 1.52 & 0.84 & 0.094 & 1.3305 & 1.7044 \\
\hline & Total & 219 & 3.22 & 1.56 & 0.106 & 3.0124 & 3.4282 \\
\hline \multirow{3}{*}{ Empathic Concern } & Carnists & 140 & 5.07 & 1.13 & 0.096 & 4.8833 & 5.2616 \\
\hline & Ethical Vegans & 79 & 5.98 & 1.02 & 0.114 & 5.7560 & 6.2114 \\
\hline & Total & 219 & 5.40 & 1.17 & 0.079 & 5.2448 & 5.5576 \\
\hline
\end{tabular}

Table 7. Study 1 ANOVA Table.

\begin{tabular}{ccccccc}
\hline & & Sum of Squares & df & F & $p$-Value & Partial Eta Squared \\
\hline \multirow{2}{*}{ SDO $_{6}$} & Between Groups & 32.810 & 1 & 30.169 & 0.000 & 0.122 \\
& Within Groups & 235.953 & 217 & & & 0.675 \\
Tpeciesism & Total & 268.802 & 218 & & & \\
& Between Groups & 358.368 & 1 & 449.996 & 0.000 & 0.140 \\
& Within Groups & 172.814 & 217 & & & \\
Empathic Concern & Total & 531.182 & 218 & \multirow{2}{*}{35.188} & 0.000 & \\
& Between Groups & 41.938 & 1 & & & \\
& Within Groups & 258.632 & 217 & & & \\
& Total & 300.570 & 218 & & &
\end{tabular}

\subsection{Study 2: Data Analysis-SSDO}

A total of 404 respondents completed the survey featuring the SSDO scale. The sample was comprised of $147(36.4 \%)$ carnists and $143(n=35.4 \%)$ ethical vegans. The remaining $114(28.2 \%)$ were either pesco-pollo vegetarians, lacto-ovo vegetarians, or vegan for reasons other than animal rights and were thus excluded from the data analyses (see Table 8 for the demographic profile of the final sample). 
Table 8. Demographic characteristics of study 2 sample $(\mathrm{N}=290)$.

\begin{tabular}{cccc}
\hline & & Frequency & Percent \\
\hline \multirow{2}{*}{ Agender } & Male & 88 & 30.3 \\
& Female & 202 & 69.7 \\
& $18-20$ & 12 & 4.1 \\
& $21-29$ & 63 & 21.7 \\
Current Relationship Status & $30-39$ & 53 & 18.3 \\
& $40-49$ & 49 & 16.9 \\
& $50-59$ & 60 & 20.7 \\
& $60-69$ & 34 & 11.7 \\
& 70 or older & 19 & 6.6 \\
& Married & 128 & 44.1 \\
& Widowed & 7 & 2.4 \\
& Divorced & 35 & 12.1 \\
& Separated & 5 & 1.7 \\
& In a domestic partnership or civil & 14 & 4.8 \\
& union & & \\
& Single, but cohabiting with a & 39 & 13.4 \\
Lignificant other & 62 & 21.4 \\
& Single, never married & 3 & 1.0 \\
& Less than high school degree & 30 & 10.3 \\
& High school degree or equivalent & (e.g., GED) & 20.0 \\
& Some college but no degree & 58 & 10.0 \\
Associate degree & 29 & 32.4 \\
& Bachelor degree & 94 & 26.2 \\
\hline Graduate degree & 76 &
\end{tabular}

\subsubsection{SSDO}

Internal consistency of this 4 -item scale $(\alpha=0.65)$ was lower than that of the full 16 -item scale $(\alpha=0.91)$. The unrotated solution of the principal axis factor analysis showed two factors, with the first factor having an eigenvalue of 1.98 and explaining $49.41 \%$ of the variance and the second factor showing an eigenvalue of 1.11 and explaining $27.79 \%$ of the variation. Together both factors explained $77.20 \%$ of the variance. The rotated factor solution, using Varimax, clearly showed two dimensions, namely SDO-Dominance and SDO Egalitarianism (see Table 9 for items means, standard deviations, and factor loadings). This outcome is not in line with Pratto et al.'s [2] findings which showed the 4-item scale to be a one-dimensional measure. To allow the comparison of $\mathrm{SDO}_{6}$ and SSDO, the 4-item measure was collapsed into a summary variable for the remaining statistical analyses.

Table 9. SSDO, scale items, item means and standard deviations, and factor loadings.

\begin{tabular}{|c|c|c|c|c|}
\hline & Item Means & SD & Factor 1 Loadings & Factor 2 Loadings \\
\hline In setting priorities, we must consider all groups. & 2.22 & 1.56 & 0.916 & \\
\hline We should not push for group equality. ${ }^{*}$ & 2.70 & 1.90 & & 0.815 \\
\hline Group equality should be our ideal. & 2.38 & 1.57 & 0.891 & \\
\hline Superior groups should dominate inferior groups. * & 1.94 & 1.53 & & 0.848 \\
\hline
\end{tabular}

Note: Pratto et al. [2]; from $1=$ extremely oppose to $10=$ extremely favor; ${ }^{*}$ reverse coded.

\subsubsection{Correlations}

The Pearson correlations between SSDO and speciesism show a moderate, highly significant, positive relationship $(\mathrm{r}=0.350 ; p=0.000)$, as well as moderate, highly significant, negative relationship between SSDO and empathic concern $(r=-0.429 ; p=0.000)$ (see Table 5 for more detail). 


\subsubsection{One-Way ANOVA}

One-way ANOVA was used to test the hypotheses. The analyses show, as theorized, that ethical vegans exhibit a statistically significant (1) lower level of SSDO ( $\mathrm{m}=1.99$; $\left.\mathrm{F}=23.133 ; p=0.000 ; \eta^{2}=0.075\right)$ than carnists $(\mathrm{m}=2.62) ;(2)$ lower level of speciesism $\left(\mathrm{m}=1.28 ; \mathrm{F}=557.257 ; p=0.000 ; \eta^{2}=0.659\right)$ than carnists $(\mathrm{m}=3.82)$; and (3) higher level of empathic concern $\left(\mathrm{m}=6.01 ; \mathrm{F}=21.709 ; p=0.000 ; \eta^{2}=0.070\right)$ than carnists $(\mathrm{m}=5.42)$. Again, the partial eta square values $\left(\eta^{2}\right)$ show medium to large effect sizes (see Tables 10 and 11 for more detail on the statistical analyses). Hence, $\mathrm{H}_{1}, \mathrm{H}_{2}$, and $\mathrm{H}_{3}$ can be supported.

Table 10. Study 2 descriptive statistics.

\begin{tabular}{cccccccc}
\hline & & & & & \multicolumn{2}{c}{ 95\% Confidence Interval for Mean } \\
\hline \multirow{2}{*}{ SSDO } & & N & Mean & SD & Std. Error & Lower Bound & Upper Bound \\
& Carnists & 146 & 2.62 & 1.19 & 0.098 & 2.4272 & 2.8160 \\
& Ethical Vegans & 142 & 1.99 & 1.01 & 0.085 & 1.8265 & 2.1629 \\
Speciesism & Total & 288 & 2.31 & 1.15 & 0.068 & 2.1794 & 2.4456 \\
& Carnists & 147 & 3.82 & 1.16 & 0.096 & 3.6333 & 4.0113 \\
& Ethical Vegans & 143 & 1.28 & 0.57 & 0.048 & 1.1837 & 1.3723 \\
Empathic Concern & Total & 290 & 2.57 & 1.57 & 0.092 & 2.3863 & 2.7491 \\
& Carnists & 147 & 5.42 & 1.06 & 0.088 & 5.2416 & 5.5883 \\
& Ethical Vegans & 143 & 6.01 & 1.10 & 0.092 & 5.8251 & 6.1889 \\
& Total & 290 & 5.71 & 1.12 & 0.064 & 5.5819 & 5.8363 \\
\hline
\end{tabular}

Table 11. Study 2 ANOVA Table.

\begin{tabular}{ccccccc}
\hline & & Sum of Squares & df & F & $p$-Value & Partial Eta Squared \\
\hline \multirow{2}{*}{$\mathrm{SDO}_{6}$} & Between Groups & 28.287 & 1 & 23.133 & 0.000 & 0.075 \\
& Within Groups & 349.713 & 286 & & & \\
\multirow{2}{*}{ Speciesism } & Total & 378.000 & 287 & & & 0.659 \\
& Between Groups & 469.239 & 1 & 557.257 & 0.000 & \\
& Within Groups & 242.511 & 288 & & & 0.070 \\
Empathic Concern & Total & 711.750 & 289 & & \\
& Between Groups & 25.406 & 1 & 21.709 & 0.000 & \\
& Within Groups & 337.047 & 288 & & & \\
\hline
\end{tabular}

\section{Discussion}

The results of our research are in line with Pratto et al.'s [2] study that found the predictive validity of the SSDO to be comparable to that of the $\mathrm{SDO}_{6}$. Although the internal reliability of the SSDO as assessed in our research $(\alpha=0.65)$ is relatively low, it is actually on the higher end when compared to Pratto et al.'s 20-country study, where $\alpha$ ranged from a low 0.34 for Turkey to a high 0.80 for the US, with a mid-point of 0.60 . More importantly, Pratto et al. [2], p. 590 used Rodriguez and Maeda's [31] formula to calculate a weighted average of $\alpha=0.65$, which shows "good internal reliability for a brief scale", and is reflected in our results. These findings are of utility to researchers as well as practitioners who are more interested in predictability and want tools that lessen data collection burdens, such as long surveys. Our research, along with Pratto et al. [2], supports that this goal is possible.

As hypothesized, the findings of the present study show that carnists display a significantly higher level of social dominance orientation than ethical vegans, regardless of whether measured by the $\mathrm{SDO}_{6}$ or SSDO. This finding is important as it demonstrates that it is legitimate to extend theories and models developed in research focusing on human social systems, hierarchies, and interactions to those that include the rest of the animal kingdom. The findings further show that carnists display a higher level of speciesism as well as a lower level of empathic concern. This is of importance to consumer researchers and social marketers as knowing a target market's level of SDO, speciesism, and empathic concern can aid in developing convincing messages designed to entice the buying or adoption by 
a specific target market of one's product(s). That is, messages that de-emphasize social dominance over animals and/or a higher need for empathic concern towards animals could, for example, aid social marketers design messages that address worldwide problems such as the impact of animal agriculture on global warming [32]. As a case in point, the Food and Agriculture Organization of the UN has identified animal agriculture as the second largest contributor to human-made greenhouse gas emissions and a leading cause of deforestation, air and water pollution, as well as biodiversity loss [33]. Considering that the human population is expected to increase from 7.7 billion in 2019 to 9.7 billion in 2049, and peak at almost 11 billion by 2100 [34], animal agriculture and its negative impacts are of growing importance, as research has shown that animal agriculture increasingly strains land, water, and energy resources across the planet. Specifically, the 70 billion land animals that need to be raised every year for human consumption [35] take up approximately $30 \%$ of the planet's ice-free land surface [36] and almost $16 \%$ of global freshwater [37]. Further, 30\% of worldwide grain production is used to feed livestock [38]. By 2050 meat consumption is expected to rise $76 \%$ and milk consumption $64 \%$ [33], which will lead to an increase of resources needed to support the industry. Turning our sight to the US market, beef consumption is a major concern, with average annual consumption leading to 1984 pounds of $\mathrm{CO}_{2}$ e (i.e., carbon dioxide equivalent). Replacing beef with plants would reduce that number by $96 \%$ or to 73 pounds of $\mathrm{CO}_{2} \mathrm{e}$ [39].

Likewise, messages de-emphasizing social dominance over animals and speciesism and/or highlighting empathic concern can also aid promoters of vegan food substitutes, vegan cosmetics, vegan cleaning products, faux leather, faux fur, faux wool, and other plant-based substitutes for commonly used products. Recent research, for example, has found that using virtual reality-defined as "a computer-generated, immersive experience that allows users to step into an interactive, virtual environment, eliciting the feeling that they are actually present in this simulated reality" (p. 2)-that allows users to share the experiences of factory-farmed pigs from birth to slaughter, as compared to video documentary, has a positive impact on the presence (defined as a user's feeling of being emersed in the virtual environment) and empathic concern and leads to a decrease in the intention of eating meat [40].

\section{Limitations and Suggestions for Future Research}

Research limitations generally lead to suggestions for future research, and we will discuss several. The first limitation relates to our sampling. As we were specifically interested in comparing carnists to ethical vegans, fairly large portions of our samples had to be excluded, namely 76 (25.8\%) in Study 1, and 114 (28.2\%) in Study 2. The respondents who were excluded fall into different categories, those who do not consume red meat but poultry and/or fish and seafood, vegetarians who either eat dairy or eggs or both, as well as vegans who are refraining from the consumption of animal-derived products for reasons other than animal rights, namely health vegans, environmental vegans, etc. In our study, neither of these sub-groups was large enough for statistical purposes, but future research should include these different categories of consumers as food choices and motivations for going vegan have big implications for commerce in terms of product and promotional messaging, and therefore provide additional opportunities for more research.

Another limitation is that both of our samples exhibited limited diversity. Although care was taken to mirror the racial makeup of US society when data were collected through the Harris Panel, this was not feasible when finalizing the data collection process through animal rights and vegan organizations. Future research should specifically focus on the recruitment of vegans who are members of racial and/or ethnic minorities to test whether our findings hold or need to be expanded.

Further, unlike Pratto et al. [2], our research showed that the 4-item SSDO captured two dimensions that mirror the dimensions of the original $\mathrm{SDO}_{6}$ scale, namely a dimension that assesses dominance and another that measures egalitarianism. Having a short scale 
that reflects the dimensionality of the long scale it is to replace might be a good feature, and future studies should explore this phenomenon.

In addition, our study was set in a single context and a single country. Although we cannot guarantee that the high predictability and low-reliability relationship will hold for every given context, it is another data point that supports Pratto et al.'s findings (2013). Future research could either take our context to other countries or test the SSDO in different consumer contexts in the US, such as environmental concern, willingness to take action addressing climate change, and other areas that are focusing on ethical consumption.

Finally, future research could also focus on developing a theoretical model that provides the basis for further extension of social dominance theory. Such a model could, for example, be used to explain gaps in other consumption theories that prevent consumers from consuming ethically.

\section{Conclusions}

Considering the well-documented growth in veganism (ethical or otherwise), the construct is bound to be studied more, and likely across disciplines. Since our research has shown that the four-item SSDO can legitimately be used for quality research that is more respectful of respondents' time, and other authors have suggested that shorter surveys may increase response rates [41], our findings are of importance for researchers tackling both theory development and applied research that focus on studying veganism and other ethical consumption choices.

Social dominance orientation has been well established as a robust concept, and even more so based on this study. In the case of this research that spans both consumer behavior and sustainability, social dominance orientation among carnists would appear to be real. And, given the nature of the construct, it is quite plausible that the orientation of carnists is likely quite ingrained and therefore persistent. It seems logical that carnists are brought up with their beliefs, whereas ethical vegans evolve into them. Since this topic comes from the domain of psychology, there would seem to be plenty of opportunities for consumer researchers to study this construct in relevant consumer behavior contexts as well. After all, our interest in doing this research is understanding the resistance to at least eating more sustainably (and ideally moving more people closer to a vegan diet).

With respect to consumer behavior (and for that matter, where it intersects sustainability, the broader field of marketing, and perhaps even public policy), many managers/decisionmakers - and certainly everyday consumers-may not be interested in the mechanics of how social dominance is manifested. They can leave this to the academics. While social dominance orientation may be strong in carnists and ingrained from childhood in many cultures, there is strong positive sentiment (especially among younger consumers, and not just the youngest) toward sustainability and "most things green" for that matter. This leaves plenty of opportunities to study the changes in the degree of social dominance orientation, the rate of change, and similar metrics.

Author Contributions: Conceptualization, K.B.; methodology, K.B., R.O.F. and B.B.; software, K.B. and B.B.; validation, R.O.F. and B.B.; formal analysis, K.B.; investigation, R.O.F.; resources, K.B.; data curation, K.B.; writing - original draft preparation, K.B.; writing-review and editing, R.O.F. and B.B.; visualization, R.O.F. and B.B.; supervision, R.O.F.; project administration, B.B.; funding acquisition, K.B. All authors have read and agreed to the published version of the manuscript.

Funding: This work was supported, in part, by the University of South Florida Research and Innovation Internal Awards Program under Grant No. 0038954. The funding source did NOT have any role in study design; in the collection, analysis and interpretation of data; in the writing of the report; and in the decision to submit the article for publication.

Institutional Review Board Statement: Ethical review and approval were waived for this study, due to the Institutional Review Board's (IRB) determination that our research meets criteria for exemption from the federal regulations as outlined by 45CFR46.101(b): Research involving the use of educational tests (cognitive, diagnostic, aptitude, achievement), survey procedures, interview procedures or 
public behavior, unless: (i) Information obtained is recorded in such a manner that human subjects can be identified, directly or through identifiers linked to the subjects; and (ii) any disclosure of the human subjects' responses outside the research could reasonably place the subjects at risk of criminal or civil liability or be damaging to the subjects' financial standing, employability, or reputation.

Informed Consent Statement: Informed consent was obtained from all subjects involved in the study.

Data Availability Statement: Data available upon request.

Conflicts of Interest: We have no known conflict of interest to disclose.

\section{References}

1. Sidanius, J.; Pratto, F. Social Dominance; Cambridge University Press: New York, NY, USA, 1999.

2. Pratto, F.; Cidam, A.; Stewart, A.L.; Zeineddine, F.B.; Aranda, M.; Aiello, A.; Chryssochoou, X.; Cichocka, A.; Cohrs, J.C.; Durrheim, K.; et al. Social dominance in context and in individuals: Contextual moderation of robust effects of social dominance orientation in 15 languages and 20 countries. Soc. Psychol. Personal. Sci. 2013, 4, 587-599. [CrossRef]

3. Jost, J.T.; Thompson, E.P. Group-based dominance and opposition to equality as independent predictors of self-esteem, ethnocentrism and social policy attitudes among African Americans and European Americans. J. Exp. Soc. Psychol. 2000, 36, 209-232. [CrossRef]

4. Rammstedt, B.; John, O.P. Measuring personality in one minute or less: A 10-item short version of the big five inventory in English and Germa. J. Res. Personal. 2007, 41, 203-212. [CrossRef]

5. Henry, P.J. College sophomores in the laboratory redux: Influences of a narrow data base on social psychology's view of the nature of prejudice. Psychol. Inq. 2008, 19, 49-71. [CrossRef]

6. Pratto, F.; Sidanius, J.; Stallworth, L.M.; Malle, B.F. Social dominance orientation: A personality variable predicting social and political attitudes. J. Personal. Soc. Psychol. 1994, 67, 741-763. [CrossRef]

7. Allen, M.W.; Wilson, M.; Ng, S.H.; Dunne, M. Values and beliefs of vegetarians and omnivores. J. Soc. Psychol. 2000, 140, 405-422. [CrossRef]

8. Dhont, K.; Hodson, G. Why do right-wing adherents engage in more animal exploitation and meat consumption? Personal Individ. Differ. 2014, 64, 12-17. [CrossRef]

9. Braunsberger, K.; Flamm, R. The case of the ethical vegan: Motivations matter when researching dietary and lifestyle choices. J. Manag. Issues 2019, 31, 228-245.

10. Feygina, I.; Jost, J.T.; Goldsmith, R.E. System justification, the denial of global warming, and the possibility of system-sanctioned change. Personal. Soc. Psychol. Bull. 2010, 36, 326-338. [CrossRef] [PubMed]

11. Häkkinen, K.; Akrami, N. Ideology and climate change denial. Personal. Individ. Differ. 2011, 70, 62-65. [CrossRef]

12. Awais, M.; Samin, T.; Awais Gulzar, M.; Hwang, J.; Zubair, M. Unfolding the association between the big five, frugality, e-mavenism, and sustainable consumption behavior. Sustainability 2020, 12, 490. [CrossRef]

13. GlobalData. Top Trends in Prepared Goods 2017: Exploring Trends in Meat, Fish and Seafood; Pasta, Noodles and Rice; Prepared Meals; Savory Deli Food; Soup; and Meat Substitutes. June 2017. Available online: https:/ / www.reportbuyer.com/product/4959 853/top-trends-in-prepared-foods-2017-exploring-trends-in-meat-fish-and-seafood-pasta-noodles-and-rice-prepared-mealssavory-deli-food-soup-and-meat-substitutes.html (accessed on 29 June 2020).

14. Parker, J. The World in 2019: The Year of the Vegan-Where Millennials Lead, Businesses and Governments Will Follow. 2018. Available online: https:/ / worldin2019.economist.com/theyearofthevegan (accessed on 29 June 2020).

15. Vegetarian Resource Group. How Many Adults Are Vegetarian? 2015. Available online: http://www.vrg.org/nutshell/faq.htm\# poll (accessed on 29 June 2020).

16. Fox, K. Here's Why You Should Turn Your Business Vegan in 2018. 27 December 2017. Available online: https: / /www.forbes. com/sites/katrinafox/2017/12/27/heres-why-you-should-turn-your-business-vegan-in-2018/\#7aaf7e5e2144 (accessed on 29 June 2020).

17. Sternlicht, A. Alternative Meat Sales Soar Amongst Pandemic. 5 May 2020. Available online: https://www.forbes.com/sites/ alexandrasternlicht/2020/05/04/alternative-meat-sales-soar-amid-pandemic/\#5e14d823edfd (accessed on 29 June 2020).

18. MarketWatch. Vegan Food Market Size: \$24.3 Billion by 2026. 2019. Available online: https://www.marketwatch.com/pressrelease/vegan-food-market-size-us-243-billion-by-2026-2019-06-18 (accessed on 26 December 2019).

19. Chiorando, M. Global Meat Substitutes Market to Exceed \$6 Billion by 2023. Available online: https:/ /www.plantbasednews. org/post/global-meat-substitutes-market-to-exceed-6-billion-by-2023 (accessed on 29 June 2020).

20. Jiang, I. Plant-Based 'Meat' is Conquering Fast Food. Here's Where You Can Get Meat Substitutes Like the beyond Burger and the Impossible Taco. 26 December 2019. Available online: https:/ / www.businessinsider.com/burger-king-tgi-fridays-chainssell-plant-based-meat-2019-5 (accessed on 29 June 2020).

21. Fox, K. Why This New York Dairy Ditched Cows after 92 Years and Started Making Nut Milks. 17 October 2017. Available online: https:/ / www.forbes.com/sites/katrinafox/2017/10/17/why-this-new-york-dairy-ditched-cows-after-92-years-andstarting-making-nut-milks/\#f186bebff82d (accessed on 29 June 2020). 
22. Janssen, M.; Busch, C.; Rödiger, M.; Hamm, U. Motives of consumers following a vegan diet and their attitudes toward animal agriculture. Appetite 2016, 105, 643-651. [CrossRef] [PubMed]

23. Joy, M. Why We Love Dogs, Eat Pigs, and Wear Cows; Conari Press: San Francisco, CA, USA, 2010.

24. Francione, G.L.; Garner, R. The Animal Rights Debate: Abolition or Regulation? Columbia University Press: New York, NY, USA, 2010.

25. Singer, P. Animal Liberation; Harper Colling Publishers, Inc.: New York, NY, USA, 2002.

26. Davis, M.H. A multidimensional approach to individual differences in empathy. JSAS Cat. Sel. Doc. Psychol. 1980, $10,85-106$.

27. Niemyjska, A.; Cantarero, K.; Byrka, K.; Bilewicz, M. Too humanlike to increase my appetite: Disposition to anthropomorphize animals relates to decreased meat consumption through empathic concern. Appetite 2018, 127, 21-27. [CrossRef]

28. Kessler, C.S.; Holler, S.; Joy, S.; Dhruva, A.; Michalsen, A.; Dobos, G. and Cramer, H. Empathy: Differences between lacto-ovovegetarians and vegans. Complement. Med. Res. 2016, 23, 95-102. [CrossRef]

29. Ho, A.K.; Sidanius, J.; Pratto, F.; Levin, S.; Thomsen, L.; Kteily, N.; Sheehy-Skeffington, J. Social dominance orientation: Revisiting the structure and function of a variable predicting social and political attitudes. Personal. Soc. Psych. Bull. 2012, 35, 538-606. [CrossRef]

30. Dhont, K.; Hodson, G.; Costello, K.; MacInnis, C. Social dominance orientation connects prejudicial human-human and humananimal relations. Personal. Individ. Differ. 2014, 61, 105-108. [CrossRef]

31. Rodriguez, M.C.; Maeda, Y. Meta-analysis of coefficient alpha. Psychol. Methods 2006, 11, 306-322. [CrossRef]

32. Dopelt, K.; Radon, P.; Davidovitch, N. Environmental effects of the livestock industry: The relationship between knowledge, attitudes, and behaviors among students in Israel. Int. J. Res. Public Health 2019, 16, 1359. [CrossRef]

33. FAO. Tackling Climate Change through Livestock: A Global Assessment of Emissions and Mitigation Opportunities. 2013. Available online: http:/ / www.fao.org/3/i3437e/i3437e.pdf (accessed on 19 July 2021).

34. United Nations Department of Economic and Social Affairs. Growing at a Slower Pace, World Population is expected to Reach 9.7 Billion in 2050 and Could Peak at Nearly 11 Billion around 2100. 2019. Available online: https://www.un.org/development/ desa/en/news/population/world-population-prospects-2019.html (accessed on 19 July 2021).

35. Sanders, B. Global Animal Slaughter Statistics and Charts. 2018. Available online: https://faunalytics.org/global-animalslaughter-statistics-and-charts / (accessed on 19 July 2021).

36. Foley, J.; Ramankutty, N.; Brauman, K.A.; Cassidy, E.S.; Gerber, J.S.; Johnston, M.; Mueller, N.D.; O'Connell, C.; Ray, D.K.; West, P.C.; et al. Solutions for a Cultivated Planet. Available online: https:/ /www.nature.com/articles/nature10452 (accessed on 19 July 2021).

37. Mekonnen, M.M.; Hoekstra, A.Y. The Green, Blue and Grey Water Footprint of Farm Animals and Animal Products. Available online: https:/ / waterfootprint.org/media/downloads/Report-48-WaterFootprint-AnimalProducts-Vol1.pd (accessed on 19 July 2021).

38. Pradhan, P.; Luedeke, M.K.B.; Reusser, D.E.; Kropp, J.P. Embedded crop calories in animal products. Environ. Res. Lett. 2013, 8, 044044. [CrossRef]

39. Eshel, G.; Shepon, A.; Noor, E.; Milo, R. Environmentally optimal, nutritionally aware beef replacement plant-based diets. Environ. Sci. Technol. 2016, 50, 8164-8168. [CrossRef]

40. Herrewijn, L.; De Groeve, B.; Cauberghe, V.; Hudders, L. VR outreach and meat reduction advocacy: The role of presence, empathic concern and speciesism in predicting meat reduction intentions. Appetite 2021, 166, 105455. [CrossRef]

41. Sindre, R.; Adler, J.; Ryden, A. Response burden and questionnaire length: Is shorter better? A review and meta-analysis. Value Health 2011, 14, 1101-1108. 